\title{
Renewable Eco-Friendly Activated Biochar from Tobacco: Chlorpyrifos Removal Studies
}

\author{
$\underline{\text { Elio Conradi Junior }}{ }^{1}$, Affonso Celso Gonçalves Junior ${ }^{1}$, Juliano Zimmermann¹, Daniel Schwantes²; Carlos

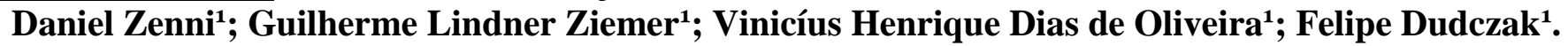 \\ ${ }^{1}$ State University of West Paraná \\ 1777 Pernambuco Street, Marechal Cândido Rondon, State of Paraná, Brazil. \\ elio.conradi@outlook.com; affonso133@hotmail.com; juliaanozimmermann@gmail.com; cdzenni@gmail.com; \\ guilhermelziemer@gmail.com; vinicius.h.2012@hotmail.com; felipe_dudczak@outlook.com \\ ${ }^{2}$ Pontificia Universidad Católica de Chile. \\ 4860 Vicuña Mackenna Avenue, postal code: 7820436 Macul, Santigo, Chile \\ daniel_schwantes@hotmail.com
}

\begin{abstract}
We evaluated the potential application of tobacco as a low-cost raw matter for the development of a new and ecological activated biochar, with the aim of chlorpyrifos adsorption. This was performed by means of characterization and testing the efficiency of the activated biochar based on tobacco from seized cigarettes. Chemically and thermally activated biochar were produced with diferent chemical modifying agents $\left(\mathrm{ZnCl}_{2}\right.$ and $\left.\mathrm{NaOH}\right)$. The treatments improved the features of adsorbent structure, with an increas of $1775 \mathrm{x}$ in $\mathrm{SSA}$ of $\mathrm{AB}-\mathrm{ZnCl}_{2}$. The adsorption of chlorpyrifos by the activated biochar seems to occur partially by chemical and partially by physical interactions between the pesticide and the surface functional groups $\mathrm{O}-\mathrm{H}, \mathrm{C}-\mathrm{H}, \mathrm{C}=\mathrm{O}, \mathrm{C}-\mathrm{C}, \mathrm{C}-\mathrm{H}, \mathrm{C}-\mathrm{O}$. The good adjustments may indicate the adsorption of mono and multilayer. The materials show great results for removal of chlorpyrifos with an estimate $\mathrm{q}_{\mathrm{m}}$ of 683.30 and $1602.40 \mu \mathrm{g} \mathrm{g}^{-1}$ for Langmuir, respectively found for $\mathrm{AB}$ and to $\mathrm{AB}-\mathrm{ZnCl}_{2}$. This way, the production of activated biochar can be an excellent alternative for the destination and use of tobacco deriving by seized cigarettes, allowing its use in remediation and decontamination of water.
\end{abstract}

Keywords: Organophosphates; Pesticides; Water Treatment; Adsorption; Smuggled Cigarettes.

\section{Introduction}

There is a worldwide interest in the maintenance of the environmental compartments quality, not only by environmentalist groups, but also by the productive systems, mainly due to the directly relation with these compartments to the global supply chain [1]. In this scenario, water resources have major importance, being specially linked to the Sustainable Development Goals proposed by the United Nations (United Nations, 2020), especially regarding goal \#6 - Clean Water and Sanitation for all. In a recent investigation conducted in Brazil that aimed to identify pesticides in water supply chains found out that $91 \%$ of the samples contained some concentration of chlorpyrifos (CPF) [2]. Among the alternatives for the remediation of water compartments, the adsorption process is a promising option, since it is a technology with effectiveness and high efficiency in the removal of organic and inorganic pollutants, besides being environment-friendly [3]. A material that currently does not have adequate destination or economic value is the cigarette seized by the Federal Revenue of Brazil in border regions of Brazil-Paraguay. The transformation of a potentially toxic waste which causes numerous environmental problems - such seized cigarrets - into modified adsorbents for water decontamination, could allow this waste to have an environmentally appropriate destination [4].

\section{Material and Methods}

\subsection{Adsorbents obtainment and preparation}

The tobacco used in this study derived from the Federal Revenue of Brazil, through cigarette seizures in western regions of the State of Paraná, South of Brazil. The tobacco was sent to the Laboratory of Environmental and Instrumental Chemistry, at the State University of Western Paraná - State of Paraná, Brazil. The tobacco was standard in 14 and 54 mesh $(0.212$ and $1.400 \mathrm{~mm})$. Two chemical activations (agents) were tested, a zinc chloride solution $\left(\mathrm{ZnCl}_{2}\right)(\mathrm{Anhydrous} \mathrm{Zinc}$ Chloride $97 \%$ P.A., $\mathrm{NEON}^{\circledR}$ ) and a sodium hydroxide $(\mathrm{NaOH})$ (Sodium Hidroxide in Micro Pearl P.A., NEON ${ }^{\circledR}$ ). 
After chemical activation, the materials were burned at a pre-set temperature $\left(750{ }^{\circ} \mathrm{C}\right.$ for 60 min, under nitrogen flow $\mathrm{N}_{2}$ ), in a FT $12001 \mathrm{Z}$ tubular oven, model FE50RPN (4000Watts - FORTELAB ${ }^{\circledR}$ ). This procedure resulted in two thermally and chemically activated biochar, named $\mathrm{AB}-\mathrm{ZnCl}_{2}$ and $\mathrm{AB}-\mathrm{NaOH}$, and one thermally activated biochar ( $\mathrm{AB}$ - thermally activated biochar), in addition to tobacco unmodified biomass ( $\mathrm{T}$ in natura). Thus, the experiment consisted of four treatments: $\mathrm{T}$ in natura, $\mathrm{AB}, \mathrm{AB}-\mathrm{ZnCl}_{2}$ and $\mathrm{AB}-\mathrm{NaOH}$. After obtaining all tobacco-based biochar, these were characterized and tested by means of adsorption studies with CPF.

\subsection{Characterization of the adsorbents}

The chemical elements (K, Ca, Mg, Cu, Fe, Mn, $\mathrm{Zn}, \mathrm{Zn}, \mathrm{Cd}, \mathrm{Pb}$ and $\mathrm{Cr}$ ) were determined by means of a nitroperchloric digestion followed by determination by atomic absorption spectrometry (FAAS), with certified standard curves for all metals (GBC 932 AA). Scanning electron microscopy (SEM), infrared (IR) spectroscopy were also performed.

For the determination of the zero load point (pHPCZ), $0.5 \mathrm{~g}$ of each material produced was weighed and $50 \mathrm{~mL}$ of 0.5 mol L-1 aqueous solution of potassium chloride $(\mathrm{KCl})$ was added with $\mathrm{pH}$ values between 2.0 and 13.0 (pH adjusted with $\mathrm{HCl}$ and $\mathrm{NaOH}-0.1$ mol L-1). The $\mathrm{pH}$ variation $(\Delta \mathrm{pH})$ occurred during the process (final $\mathrm{pH}-$ initial $\mathrm{pH}$ ) was then determined. When plotting the data, $\mathrm{pHPCZ}$ corresponded to the value at which the dependent variable $(\Delta \mathrm{pH})$ exceeded the value of the independent variable (initial $\mathrm{pH}$ ) - adapted methodology [5].

\subsection{Studies on the dose of adsorbent and ph effect on the adsorption process}

In order to evaluate the possible interactions between the tobacco adsorbent doses and the $\mathrm{pH}$ of the solution on CPF adsorption, a Central Composite Design (CCD) was used [6]. Different adsorbent masses were evaluated ranging from 5.0 to $25.0 \mathrm{~g} \mathrm{~L}-1$ while the $\mathrm{pH}$ was evaluated in the range on 3.0 a 7.0 , as described by the matrix proposed by [7]. The results obtained in the aforementioned tests were tabulated and evaluated according to multivariate analysis by using the software Statistica 7® (StatSoft, 2004), which was used for Analysis of Variance (ANOVA) and the generation of response surface graphs. The mean values of CPF removal (qe and \%) were also evaluated by using the software Sisvar 5.6 [8].

\subsection{Kinetics, equilibrium and thermodynamics studies on chlorpyrifos adsorption process}

Erlenmeyers flasks, $200 \mathrm{mg}$ of the tobacco adsorbents were set in contact with $50 \mathrm{~mL}$ of CPF solution $(1000 \mu \mathrm{g} \mathrm{L}-1)$ at $\mathrm{pH} 5.0$ [both of these conditions were obtained in previously tests (item 2.6)]. In this study, each erlenmeyer corresponded to a specific time interval $(10,20,30,40,50,60,80,100,120,140$ and $180 \mathrm{~min})$. After stirring, samples were taken for liquid-liquid extraction (10:1) (previously described), and the remaining concentration (Ce) of CPF was determinated by GC-ECD. The obtained results were studied by using the models of pseudo-first order, pseudo-second order, Elovich and intraparticle diffusion.

Equilibrium isotherms were obtained by means of adsorption studies. For this purpose, $200 \mathrm{mg}$ of adsorbent was added to $125 \mathrm{~mL}$ erlenmeyers flask together with $50 \mathrm{~mL}$ of $\mathrm{CPF}$ solution at $\mathrm{pH} 5.0$, in increasing concentrations of CPF: 100, 300, $600,900,1200,1500,1800,2100$ and $2700 \mu \mathrm{g} \mathrm{L}-1$. These flasks were stirred for $100 \mathrm{~min}$ at $200 \mathrm{rpm}$ and $25^{\circ} \mathrm{C}$. Then, samples were taken for liquid-liquid extraction (previously described) and further Ce determination by GC-ECD. From the obtained results, the adsorption isotherms were evaluated by using the nonlinear models of Langmuir [9], Freundlich [10], Dubinin-Radushkevich [11] Sips [12], Temkin [13] and Liu [14]. The adsorption isotherms were constructed in three temperature conditions, 25,30 and $35^{\circ} \mathrm{C}$. The experimental conditions of this test were: adsorbent mass of $200 \mathrm{mg}$ in $50 \mathrm{~mL}$ of CPF solution of $1000 \mu \mathrm{g} \mathrm{L}-1$ at $\mathrm{pH} 5.0,200 \mathrm{rpm}$, and $100 \mathrm{~min}$ of stirring. Then, samples were taken for liquid-liquid extraction (previously described) and further Ce determination by GC-ECD. The Gibbs free energy $\left(\Delta \mathrm{G}^{\circ}\right)$, enthalpy $\left(\Delta \mathrm{H}^{\circ}\right)$ and entropy $\left(\Delta S^{\circ}\right)$ were calculated in order to evaluate the thermodynamics of CPF adsorption [15].

\section{Results And Discussion}

The AB-NaOH, obtained the highest pHPZC, the chemical activation (by a strong base) in addition to the thermal activation resulted in an even higher increase of the pHPZC value [6]. FT-IR shows that functional groups from macromolecules such as lignin, proteins, carboxyl, phenolic groups and aromatic modes (mainly skeleton of cellulose and lignin) are exposed in tobacco-based adsorbents (Figura 1). The characteristics observed from SEM might suggest that the 
biochar materials developed from tobacco have enhanced characteristics of adsorption, which could be a good indicator for the adsorption of CPF [16]. The specific surface area (SSA) followed the order: $\mathrm{AB}-\mathrm{ZnCl} 2>\mathrm{AB}>\mathrm{AB}-\mathrm{NaOH}>\mathrm{T}$ in natura, with following values: $479.4,83.6,76.61$ and $0.27 \mathrm{~m} 2 \mathrm{~g}-1$, respectively.

According to the results found for the biochar from tobacco, none statistic influence for the CPF adsorption regarding the studied $\mathrm{pH}$ range, or the interaction between adsorbent doses and $\mathrm{pH}$ range were found. Thus, it can be concluded that the CPF adsorption process depends only on the adsorbent dose; the $\mathrm{pH}$ solution, in the studied range (3.0 to 7.0), do not influence CPF adsorption process. In genneral, the highest adsorbed amount (qe) as well as the highest removal of CPF, are found by using tobacco-based biochar in doses of around $4.0 \mathrm{~g} \mathrm{~L}-1$. This can be considered a great advantage, i.e., using low doses of tobacco-adsorbent (4.0 g L-1) one liter of solution containing CPF can be decontaminated.
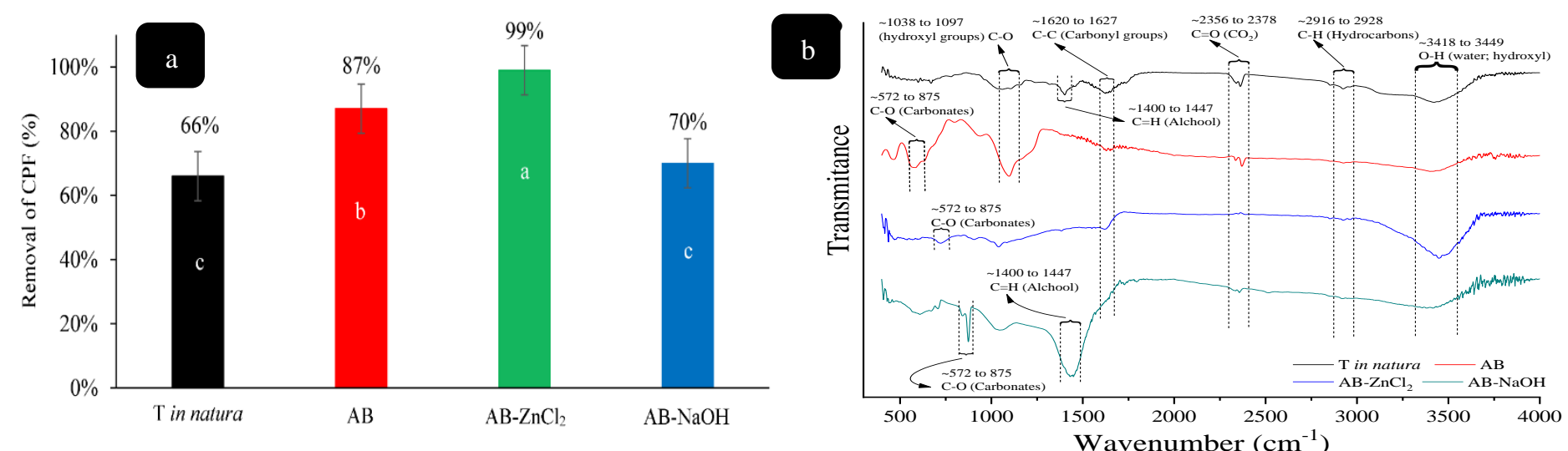

Fig. 1: Means obtained for the removal of CPF in the CCD experiment (a) and infrared spectrum analysis from 4000 to $500 \mathrm{~cm}^{-1}$ for the adsorbents $\mathrm{T}$ in natura, $\mathrm{AB}, \mathrm{AB}-\mathrm{ZnCl}_{2}$ and $\mathrm{AB}-\mathrm{NaOH}(\mathrm{b})$. Notes: Different letters inside the bars indicate statistical difference among treatments at $5 \%$ by Tukey test.

It is important to stand out the results obtained for $\mathrm{AB}-\mathrm{ZnCl}_{2}$, with a fast adsorption of $\mathrm{CPF}$, with more than $95 \%$ of $\mathrm{CPF}$ removal ocurring within $10 \mathrm{~min}$. A similar performance is also observed for $\mathrm{AB}-\mathrm{NaOH}$, with the equilibrium being reach in about $80 \mathrm{~min}$. In contrast, for $\mathrm{T}$ in natura and $\mathrm{AB}$ the equilibrium is not established even after 180 min, with very low adsorption rates being observed.

It is observed that the adsorption of $\mathrm{CPF}$ is exothermic for $\mathrm{T}$ in natura and for $\mathrm{AB}$, in function to the negative values of $\Delta \mathrm{Ho}(\Delta \mathrm{Ho} \mathrm{T}$ in natura $=-684 \mathrm{~kJ}$ mol- $1 ; \Delta \mathrm{Ho} \mathrm{AB}=-859 \mathrm{~kJ}$ mol-1 $)$; for $\mathrm{AB}-\mathrm{NaOH}$ are observed positive values of $\Delta \mathrm{Ho}(\Delta \mathrm{Ho}$ $\mathrm{AB}-\mathrm{NaOH}=993 \mathrm{~kJ}$ mol-1) indicating an endotermic process [17]. The values of $\Delta \mathrm{Go}<0$, indicate that the adsorption of $\mathrm{CPF}$ onto $\mathrm{T}$ in natura, $\mathrm{AB}-\mathrm{NaOH}$ and $\mathrm{AB}$ is a spontaneous process (Hamid et al., 2014). The negative values found for Gibbs free energy, i.e., $\Delta \mathrm{Go}>0$, suggest that regarding this parameter, CPF adsorption was energetically favourable and spontaneous at the studied range of temperatures $(25$ to $35 \mathrm{oC})$ for $\mathrm{T}$ in natura, $\mathrm{AB}-\mathrm{NaOH}$ and $\mathrm{AB}$.

The goodness of the fit found for Langmuir, Freundlich and Sips for AB, AB-ZnCl2 and AB-NaOH, could suggest that these materials pass through cooperative adsorption where initially adsorption occurs in monolayers (in high affinity sites), with the interaction between CPF molecules and the surface of the tobacco activated biochar and, in a second moment, with the formation of multilayers, from the interactions between adsorbate-adsorbent and absorbate-adsorbate. The materials show great results for removal of chlorpyrifos with an estimate qm of 683.30 and $1602.40 \mu \mathrm{gg}-1$ for Langmuir, respectively found for $\mathrm{AB}$ and to $\mathrm{AB}-\mathrm{ZnCl} 2$. The values of sorption energy (E) for all studied adsorbents are higher than $8 \mathrm{~kJ}$ mol-1, with a predominance of high energy bonds due to chemical forces, suggesting chemical sorption [18]. The best ajustment for Liu was observed for $\mathrm{AB}$, with adj-R2 of 0.981 and with low values for $\sigma$ in all parameters. In this specific case, the values of qmax reached $913 \mu \mathrm{g}$ g-1, followed by $\mathrm{AB}-\mathrm{NaOH}$, with qmax reaching $689 \mu \mathrm{g}$ g-1, indicating the great potential of tobacco biochar for CPF removal. 


\section{Conclusion}

The proposed procedure for thermal and chemical modification of tobacco biomass successfully generated activated biochar with excellent characteristics for the removal of chlorpyrifos from waters. The use of $4 \mathrm{~g}$ of adsorbent is sufficient to remediate $1 \mathrm{~L}$ of water contaminated by chlorpyrifos. The adsorption of chlorpyrifos seems to occur by physical and chemical bonds, in a favourable and spontaneous process. This statement is due to the excellent fits found by the following models: pseudo-first, pseudo-second order, Langmuir, Freundlich, Sips, Dubinin-Radushkevich, Temkin and Liu. Also, it is evidenced the formation of mono and multilayers of chlorpyrifos in the adsorbents surface.

\section{Acknowledgements}

This study was financed in part by the Coordenação de Aperfeiçoamento de Pessoal de Nível Superior - Brasil (CAPES) - Finance Code 001. The authors thank the Conselho Nacional de Desenvolvimento Científico e Tecnológico (CNPq) for the scholarship of productivity research.

\section{References}

[1] N. C. Ban, "Systematic Conservation Planning: A Better Recipe for Managing the High Seas for Biodiversity Conservation and Sustainable Use," Conserv. Lett., vol. 7, no. 1, pp. 41-54, 2013.

[2] Pública. (2019, May 5). "Coquetel” com 27 pesticidas foi achado na água de 1 em cada 4 municípios ("Cocktail” with 27 pesticides was found in the water of 1 in 4 municipalities) [Online]. Available: http://apublica.org/2019/04/coquetelcom-27-agrotoxicos-foi-achado-na-agua-de-1-em-cada-4-municipios/.

[3] A. C. Gonçalves Jr, "Biosorption of Cu (II) and Zn (II) with açaí endocarp Euterpe oleracea M. in contaminated aqueous solution," Acta Sci. Technol., vol. 38, n. 3, pp. 361-370, 2016.

[4] M. Cooke, "The Chemical Components of Tobacco and Tobacco Smoke," Chromatographia, vol.71, pp. 977, 2010.

[5] B. Barros Neto, Como fazer experimentos: Aplicações na Ciência e na Indústria (How to experiments: Application in Science and Industry). Porto Alegre, RS: Bookman, 2010.

[6] A. M. S. Mimura, "Utilization of rice husk to remove $\mathrm{Cu}^{2+}, \mathrm{Al}^{3+}, \mathrm{Ni}^{2+}$ and $\mathrm{Zn}^{2+}$ from wastewater," Quím. Nova, vol. 33, no. 6, pp. 1279-1284, 2010.

[7] E. Conradi Jr., "Development of renewable adsorbent from cigarettes for lead removal from water," J. Environ. Chem. Eng., vol. 7, no. 4, pp. 103200, 2019.

[8] D. F. Ferreira, "Sisvar: a computer statistical analysis system," Ciênc. Agrotec., vol. 35, no. 6, p. 1039-1042, 2011.

[9] I. Langmuir, "The constitution and fundamental properties of solids and liquids. II. Liquids," J. Am. Chem. Soc., vol. 39, no. 9, pp. 1848-1906, 1917.

[10] H. M. F. Freundlich, "Over the adsorption in solution," J. Phys. Chem., vol. 57, pp. 385-471, 1906.

[11] M. M. Dubinin, "The equation of the characteristic curve of activated charcoal," Proc. Natl. Acad. Sci. USA, vol. 55, pp. 331, 1947.

[12] R. Sips, "Combined form of Langmuir and Freundlich equations," J. Chem. Phys., vol. 16, no. 5, pp. 490-495, 1948.

[13] M. I. Temkin, "Kinetics of ammonia synthesis on promoted iron catalysts," Acta Physiochim. URSS, vol. 12, pp. 327$356,1940$.

[14] Y. Liu, "A general model for biosorption of $\mathrm{Cd}^{2+}, \mathrm{Cu}^{2+}$ and $\mathrm{Zn}^{2+}$ by aerobic granules," J. Biotechnol., vol. 102, no. 3, pp. 233-239, 2003.

[15] A. A. Farghali, "Preparation, decoration and characterization of graphene sheets for methyl green adsorption," J. Alloys Compd., vol. 555, pp. 193-200, 2013.

[16] A. Debrassi, "Adsorption of congo red dye by hydrophobic o-carboxymethyl chitosan derivatives," Quím. Nova, vol. 34, no. 5, pp. 764-770, 2011.

[17] I. M. Reck, "Removal of tartrazine from aqueous solutions using adsorbents based on activated carbon and Moringa oleifera seeds," J. Clean. Prod., vol. 171, pp. 85-97, 2018.

[18] M. N. Rashed, "Preparation and characterization of green adsorbent from waste glass and its application for the removal of heavy metals from well water," Adv. Environ. Res., vol. 7, no. 1, pp. 53-71, 2018. 